Article

\title{
Prognostic Impact of PD-L1 Expression in pN1 NSCLC: A Retrospective Single-Center Analysis
}

\author{
Florian Eichhorn ${ }^{1,2, *}$, Mark Kriegsmann 2,3 ${ }^{\mathbb{D}}$, Laura V. Klotz ${ }^{1,2}$, Katharina Kriegsmann ${ }^{4}$, Thomas Muley ${ }^{2,5}$, \\ Christiane Zgorzelski ${ }^{3}$, Petros Christopoulos ${ }^{2,6}$, Hauke Winter ${ }^{1,2}$ and Martin E. Eichhorn ${ }^{1,2}$ \\ 1 Department of Thoracic Surgery, Thoraxklinik, Heidelberg University, 69117 Heidelberg, Germany; \\ laura.klotz@med.uni-heidelberg.de (L.V.K.); Hauke.Winter@med.uni-heidelberg.de (H.W.); \\ martin.eichhorn@med.uni-heidelberg.de (M.E.E.) \\ 2 Translational Lung Research Center, German Center for Lung Disease (DZL), 69120 Heidelberg, Germany; \\ Mark.Kriegsmann@med.uni-heidelberg.de (M.K.); Thomas.Muley@med.uni-heidelberg.de (T.M.); \\ Petros.Christopolous@med.uni-heidelberg.de (P.C.) \\ 3 Institute of Pathology, Heidelberg University Hospital, 69120 Heidelberg, Germany; \\ christiane.zgorzelski@med.uni-heidelberg.de \\ 4 Department of Hematology, Oncology and Rheumatology, Heidelberg University, \\ 69117 Heidelberg, Germany; Katharina.Kriegsmann@med.uni-heidelberg.de \\ 5 Section Translational Research (STF), Thoraxklinik, Heidelberg University, 69117 Heidelberg, Germany \\ 6 Department of Thoracic Oncology, Thoraxklinik, Heidelberg University Hospital, 69120 Heidelberg, Germany \\ * Correspondence: florian.eichhorn@med.uni-heidelberg.de
}

check for updates

Citation: Eichhorn, F.; Kriegsmann, M.; Klotz, L.V.; Kriegsmann, K.;

Muley, T.; Zgorzelski, C.;

Christopoulos, P.; Winter, H.;

Eichhorn, M.E. Prognostic Impact of PD-L1 Expression in pN1 NSCLC: A Retrospective Single-Center Analysis. Cancers 2021, 13, 2046. https:/ / doi.org/10.3390/cancers13092046

Academic Editor: Akiteru Goto

Received: 19 March 2021

Accepted: 19 April 2021

Published: 23 April 2021

Publisher's Note: MDPI stays neutral with regard to jurisdictional claims in published maps and institutional affiliations.

Copyright: (c) 2021 by the authors. Licensee MDPI, Basel, Switzerland. This article is an open access article distributed under the terms and conditions of the Creative Commons Attribution (CC BY) license (https:/ / creativecommons.org/licenses/by/ $4.0 /)$.
Simple Summary: The analysis of prognostic biomarkers (e.g., PD-L1) helps to define treatment for lung cancer patients. To date, these markers have only been examined in metastatic or inoperable situations. We analyzed the PD-L1 expression-levels of tumors from 277 lung cancer patients that underwent curative intent surgery. PD-L1 was identified as a prognostic factor, depending on histologic subtype.

Abstract: The programmed death-ligand 1 (PD-L1) plays a crucial role in immunomodulatory treatment concepts for end-stage non-small cell lung cancer (NSCLC). To date, its prognostic significance in patients with curative surgical treatment but regional nodal metastases, reflecting tumor spread beyond the primary site, is unclear. We evaluated the prognostic impact of PD-L1 expression in a surgical cohort of 277 consecutive patients with pN1 NSCLC on a tissue microarray. Patients with PD-L1 staining (clone SP263) on $>1 \%$ of tumor cells were defined as PD-L1 positive. Tumor-specific survival (TSS) of the entire cohort was $64 \%$ at five years. Low tumor stage $(p<0.0001)$ and adjuvant therapy ( $p=0.036$ ) were identified as independent positive prognostic factors in multivariate analysis for TSS. PD-L1 negative patients had a significantly better survival following adjuvant chemotherapy than PD-L1 positive patients. The benefit of adjuvant therapy diminished in patients with PD-L1 expression in more than $10 \%$ of tumor cells. Stratification towards histologic subtype identified PD-L1 as a significant positive predictive factor for TSS after adjuvant therapy in patients with adenocarcinoma, but not squamous cell carcinoma. Routine PD-L1 assessment in curative intent treatment may help to identify patients with a better prognosis. Further research is needed to elucidate the predictive value of PD-L1 in an adjuvant setting.

Keywords: lung cancer; PD-L1; adjuvant therapy; surgery; immunotherapy; NSCLC

\section{Introduction}

Lung cancer is the world's leading cause of cancer-mortality [1]. Surgery plays a key-role in the treatment. More than one-third of patients experience a relapse of disease, even after radical tumor resection in combination with systematic mediastinal and hilar lymph node dissection [2]. Nodal metastases have been repetitively identified as a strong predictive factor for survival. Five-year survival ranges from 50\% in N1-positive to $30 \%$ or 
less in patients with N2-disease [3,4]. To date, adjuvant chemotherapy is recommended as standard treatment for any $\mathrm{pN}$-stage and results in a survival benefit of only approximately $5 \%[5,6]$. The decision for adjuvant chemotherapy does not take the tumor histology or potential therapeutic targets (e.g., actionable mutation profiles) into account.

To date, therapies targeting the immune system are routinely used in patients with locally advanced or metastatic disease only [7-9]. Individualized systemic treatment concepts have not yet been transferred to early lung cancer treatment. However, observed relapse rates in up to two-thirds of the patients, even after complete tumor resection, underline the urge for novel multimodal therapeutic approaches in potentially curable tumor stages $[10,11]$. Recently, impressive tumor responses to neoadjuvant immunotherapy have been reported $[12,13]$. However, proof of the therapeutic efficacy of adjuvant immunotherapy is unknown with a lack of reliable results in large scale patient cohorts [14,15]. It is also unclear whether the expression of the programmed death-ligand (PD-L1), which is routinely used to predict the benefit from immunotherapy in non-operable non-small cell lung cancer (NSCLC) [16], is of prognostic relevance for adjuvant lung cancer treatment. Consequently, PD-L1 is not routinely analyzed in early lung cancer, nor does it currently guide the decision towards adjuvant treatment after surgery.

We reviewed surgical patients with a pN1 NSCLC. All tumors were immunohistochemically evaluated for PD-L1 expression on a tissue microarray (TMA). Data were analyzed for a possible prognostic impact of PD-L1 expression and other clinicopathological factors associated with outcomes in order to identify cases with a presumably higher susceptibility to immunomodulatory treatment.

\section{Materials and Methods}

\subsection{Patient Selection}

Surgical specimens from 317 consecutive patients with pN1 NSCLC, who were treated at the Thoraxklinik in Heidelberg between January 2010 and December 2016, were reviewed by the author (FE) and the institutional pathologist (MK). All patients had undergone primary curative intent thoracic surgery (complete anatomical tumor resection in combination with systematic mediastinal and hilar lymph node dissection). Complete information on staging and follow-up were available from the institutional database. Patients with neoadjuvant chemotherapy or incomplete resections, as well as those who died independently from tumor progression within 90 days after surgery, were excluded from the analysis. The 7th edition of the TNM- system was used, as it was valid throughout the treatment period in determining primary surgical treatment and adjuvant therapy.

The tissue was provided by the tissue bank of the National Center for Tumor Diseases (NCT, Heidelberg, Germany). The analysis was performed in accordance with the ethical regulations of the NCT tissue bank, defined by the local ethics committee (S-174/2019). Diagnoses were made according to the recommendations of the 2015 world health classification of tumors of the lung, thymus and heart [17]. Inclusion criteria were as follows: full availability of both tumor tissue and adjacent normal lung tissue and tumor cell quality for conclusive immunohistochemical staining and diagnostic processing (tumor cell content $\geq 10 \%$ tissue area). Finally, samples from 277 of 317 patients were eligible for further analysis.

\subsection{Tissue Processing and Immunohistochemistry}

Tissue microarrays (TMA) were prepared as described previously $[18,19]$. In brief, two cylindrical cores measuring $1 \mathrm{~mm}$ in diameter from the tumor center, invasive margin and periphery were extracted from the donor block and subsequently transferred to a receiver block using an automatic TMA-roboter (TMA Grand Master, 3D Histech, Budapest, Hungary). Tissue sections were stained with the antibody clone SP263 (RTU, CE IVD) on an automated stainer (Benchmark XT, Roche, Mannheim, Germany). PD-L1 staining was evaluated according to current recommendations for lung cancer [20]. Results were recorded as the percentage of positive tumor cells for each TMA core (tumor proportion 
score). PD-L1 was determined positive if $1 \%$ of tumor cells were stained positive. Subsequent analysis evaluated cut-offs of $\geq 10 \%$ and $\geq 50 \%$ to assess the impact of PD-L1 at different proportion scores. The distribution of PD-L1 positive tumor cells was analyzed for both the tumor center and the invasive margin.

\subsection{Statistical Analysis}

Tumor-specific survival (TSS) was defined as the time from the date of surgery to the date of tumor-related death or last follow-up in censored, alive patients. Disease-free survival (DFS) was defined as the time from the date of surgery until the date of first detection of tumor relapse. Data were collected and analyzed using SPSS version 25 (IBM Corporation, Armonk, NY, USA). Survival was calculated using the Kaplan-Meier product method, while the log rank-test was used to calculate univariate differences. The Coxregression model was used for multivariate analysis. Rates and proportions were analyzed using the chi-square or Fisher's exact test. A $p$-value of less than 0.05 was considered statistically significant.

\section{Results}

\subsection{Clinical Patient Characteristics}

Data from 277 patients (186 male $(67.1 \%))$, with a mean ( \pm standard deviation (SD)) age of $65,1( \pm 9.7)$ years were retrospectively analyzed (Table 1$)$. Lobectomy was performed in 178 patients $(64.3 \%)$, bilobectomy in 18 patients $(6.5 \%)$ and pneumonectomy in 81 patients (29.2\%). There were $151(54.5 \%)$ squamous cell carcinomas and $126(45.5 \%)$ adenocarcinomas.

174 patients $(62.8 \%)$ received adjuvant platinum-based chemotherapy. Systemic treatment was not administered in 103 patients (37.2\%). The main reasons for deciding against chemotherapy were comorbidities $(68.9 \%)$ or refusal $(25.2 \%)$.

Table 1. Patient characteristics.

\begin{tabular}{lc}
\hline Variable & $n \mathbf{( \% )}$ \\
\hline No. of patients & $277(100 \%)$ \\
Gender & $186(67.1 \%)$ \\
Male & $91(32.9 \%)$ \\
Female & $65.1(40-89)$ \\
\hline Age, years: mean (range) & $142(51.3 \%)$ \\
$\quad<65$ years & $135(48.7 \%)$ \\
$\quad>65$ years & \\
\hline Performance status & $213(76.9 \%)$ \\
ECOG 0 & $64(23.1 \%)$ \\
ECOG 1 & \\
\hline Histology & $151(54.5 \%)$ \\
Squamous cell carcinoma & $126(45.5 \%)$ \\
Adenocarcinoma & \\
\hline Surgical procedure & $178(64.3 \%)$ \\
Lobectomy & $18(6.5 \%)$ \\
Bilobectomy & $81(29.2 \%)$ \\
Pneumonectomy & \\
\hline Tumor stage & $25(9.0 \%)$ \\
pT1a/b & $131(47.3 \%)$ \\
pT2a/b & $79(28.5 \%)$ \\
pT3 & $42(15.2 \%)$ \\
pT4 &
\end{tabular}


Table 1. Cont.

\begin{tabular}{lc}
\hline Variable & $n \mathbf{( \% )}$ \\
\hline Adjuvant chemotherapy & $174(62.8 \%)$ \\
Yes & $103(37.2 \%)$ \\
No & \\
\hline PD-L1 assessment & $146(52.7 \%)$ \\
Positive at any threshold & $146(52.7 \%)$ \\
$>1 \%$ of Tumor cells positive & $97(35.0 \%)$ \\
$>10 \%$ of tumor cells positive & $53(19.1 \%)$ \\
$>50 \%$ of tumor cells positive & $131(47.3 \%)$ \\
negative & $163(58.8 \%)$ \\
\hline First site of recurrence at Follow up & 31 of $114(27.2 \%)$ \\
No recurrence & 61 of $114(53.5 \%)$ \\
Local & 22 of $114(19.3 \%)$ \\
Single distant & $64 \%$ \\
Multiple & $58 \%$ \\
\hline Tumor-specific survival (5-year; $\%)$ & \\
Disease free survival (5-year; $\%)$ & \\
\hline Eastern Cooperative Oncology Group. & \\
\hline
\end{tabular}

\subsection{PD-L1 Assessment}

PD-L1 was found to be positive ( $\geq 1 \%$ positive tumor cells) in 146 patients $(52.7 \%)$. Mean expression level was 20\% (minimum 1\%, maximum 100\%). PD-L1 staining was found to be positive in 1-9\% of tumor cells in 49 patients (17.7\%), 10-49\% of tumor cells in 44 patients (15.9\%) and in $50-100 \%$ of tumor cells in 53 patients $(19.1 \%)$.

PD-L1 expression was more frequently observed in squamous cell carcinoma than adenocarcinoma $(60.3 \%$ vs. $43.7 \% ; p=0.008)$ and more often in patients younger than 65 years $(60.5 \%$ vs. $44.4 \% ; p=0.008)$. Positive PD-L1 status was more frequent in patients with better performance status; however, this was not significant (ECOG 0 vs. ECOG 1, $55.8 \%$ vs. $42.2 \%, p=0.064$ ). A higher rate of PD-L1 positive tumors was found in patients that received adjuvant chemotherapy compared to the subgroup without adjuvant therapy (58.0\% vs. $43.7 \%$; 0.025). PD-L1 was equally distributed throughout all tumor stages $(52.6 \%$ (stage II) vs. $52.9 \%$ (stage III), $p=1.0$ ).

PD-L1 positive tumor cells were exclusively found in the tumor core in 19 of 146 patients, in the invasive zone in 8 of 146 patients and in both compartments in 119 of 146 patients (Figure 1). Among these, 25 patients $(21.0 \%)$ showed a predominant distribution of PD-L1 positive tumor cells in favor of the tumor core and 64 patients $(53.8 \%)$ of the invasive margin. Thirty PD-L1 positive patients (25.2\%) showed an equal staining intensity.

The calculated difference of PD-L1 expression levels in the tumor core and invasive zone was more than $1 \%$ in 51 patients $(34.9 \%)$, more than $10 \%$ in 37 patients $(25.3 \%)$, more than $25 \%$ in 13 patients $(8.9 \%)$ and more than $50 \%$ in 15 patients $(10.3 \%)$.

\subsection{Prognostic Factors for Long-Term Survival and Relapse}

The mean follow-up was 52 months with 169 (61.0\%) of the patients still alive. TSS of the entire cohort was $64 \%$ at five years. Adjuvant chemotherapy significantly improved survival $(70.0 \%$ vs. $54.2 \%$ at five years, $p=0.014)$ in the univariate analysis. Multivariate analysis of the entire cohort confirmed adjuvant chemotherapy $(p=0.036)$ and low tumor stage $(p<0.0001)$ as independent positive predictive factors for survival. A trend towards superior survival was observed for patients with squamous cell histology $(p=0.063)$ (Table 2). 


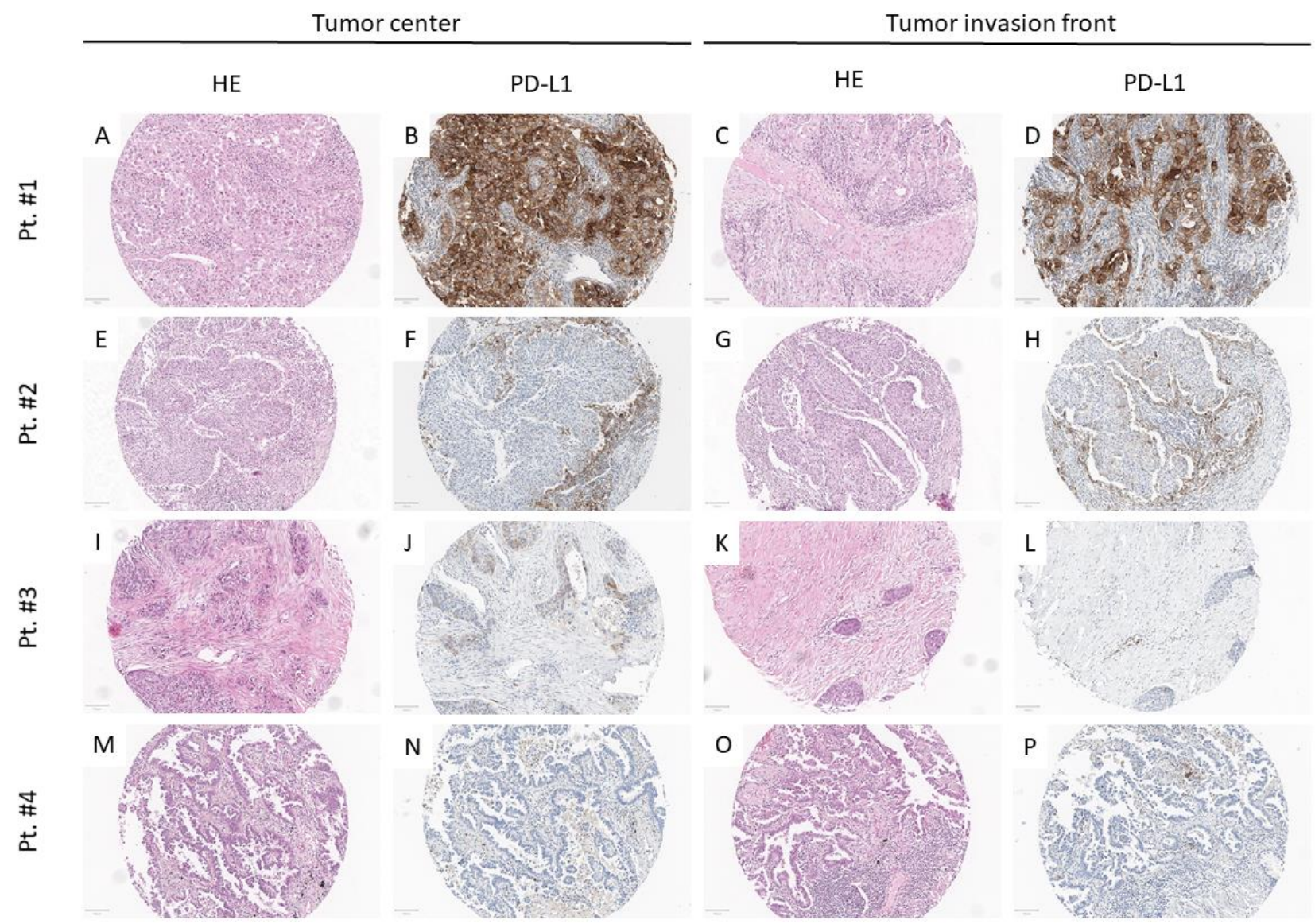

Figure 1. Examples of PD-L1 positive and PD-L1 negative tumors: Four patient samples (rows) from the tumor center (first and second column) and the respective invasion front (third and fourth column) stained with Hematoxylin and Eosin (A,E,I,M,C,G,K,O) and Programmed Cell Death Ligand 1-PD-L1; (B,F,J,N,D,H,L,P) are outlined. PD-L1 was either positive in the tumor center $(\mathbf{A}, \mathbf{B})$ and the invasion front $(\mathbf{C}, \mathbf{D}),(\mathrm{pt}$. \#1), at the invasion front $(\mathbf{G}, \mathbf{H})$ but not in the tumor center $(\mathbf{E}, \mathbf{F})$, (pt. \#2), in the tumor center $(\mathbf{I}, \mathbf{J})$ but not at the tumor invasion front (K,L), (pt. \#3) or negative in both (M-P), (pt. 4). Magnification: $100 \times$, Scale bar: $100 \mu \mathrm{m}$.

Positive PD-L1 staining determined at a threshold of $1 \%$ showed a trend towards improved survival in the entire cohort $(70.3 \%$ vs. $57.4 \%, p=0.07)$ in univariate analysis (Figure 2).

Table 2. Multivariate analysis of prognostic factors for Tumor-Specific Survival.

\begin{tabular}{|c|c|c|c|}
\hline \multirow{2}{*}{ Variable } & \multicolumn{3}{|c|}{ Tumor-Specific Survival } \\
\hline & HR & $95 \% \mathrm{CI}$ & $p$-Value \\
\hline $\begin{array}{l}\text { Histology } \\
\text { SCC vs. AC }\end{array}$ & 0.67 & {$[0.43-1.02]$} & 0.063 \\
\hline $\begin{array}{c}\text { Adjuvant chemotherapy } \\
\text { No vs. Yes }\end{array}$ & 1.56 & [1.03-2.37] & 0.036 \\
\hline $\begin{array}{l}\text { Tumor Stage } \\
\text { IIA/IIB vs. IIIA }\end{array}$ & 0.43 & {$[0.28-0.64]$} & $<0.0001$ \\
\hline $\begin{array}{c}\text { Sex } \\
\text { Male vs. female } \\
\text { PD-L1-status }\end{array}$ & 1.14 & {$[0.74-1.78]$} & 0.55 \\
\hline $\begin{array}{l}\text { Negative vs. positive } \\
\text { (at any cut-off) }\end{array}$ & 1.29 & {$[0.86-1.93]$} & 0.22 \\
\hline $\begin{array}{l}\text { Age } \\
>65 \text { years vs. }<65 \text { years }\end{array}$ & 1.26 & {$[0.84-1.94]$} & 0.25 \\
\hline
\end{tabular}


Low tumor stage and adjuvant chemotherapy treatment were identified as individual factors with a significant positive impact on tumor-specific survival. Squamous cell histology showed a trend towards better outcomes. AC, adenocarcinoma; SCC, squamous cell carcinoma; CI, confidence interval; HR, Hazard Ratio.

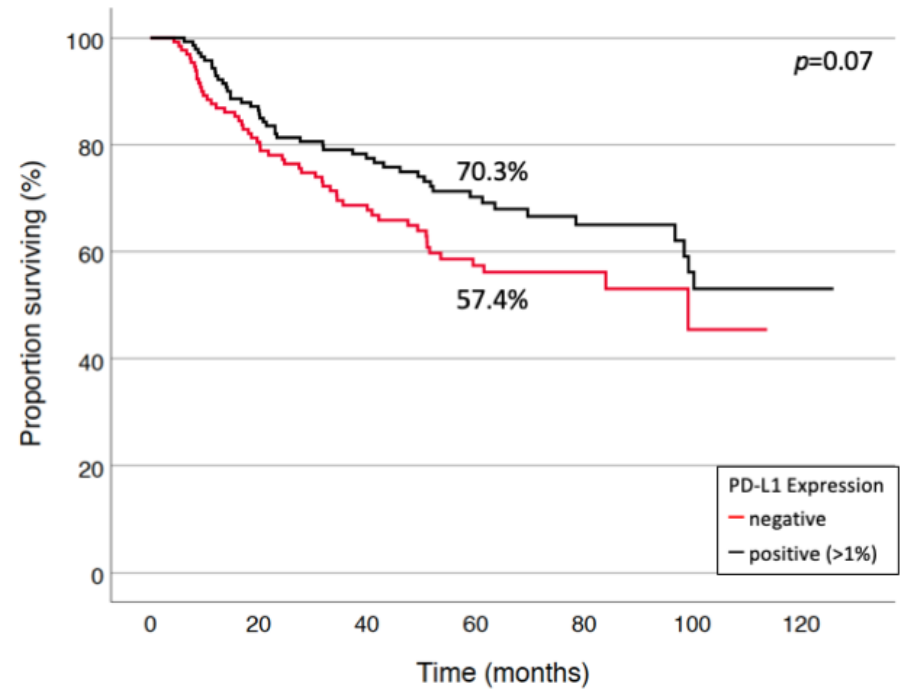

Figure 2. Tumor-specific survival by PD-L1 status. Patients with positive PD-L1 expression $(n=146)$ on tumor cells had a trend towards better 5-year survival $(70.3 \%$ vs. $57.4 \%)$ in the entire cohort $(n=277)$.

The proportion of PD-L1 positive patients was higher in the chemotherapy cohort (58.0\% vs. $43.6 \%, p=0.025)$.

Adjuvant therapy significantly improved survival in PD-L1 negative patients $(p=0.042)$. Patients with positive PD-L1 status (at a threshold of 1\%) experienced only an insignificant trend towards improved survival by chemotherapy. Adjuvant chemotherapy did not improve survival of patients with positive PD-L1 immunostaining in more than $10 \%$ of the tumor cells ( $p=0.995$; Figure 3$)$.

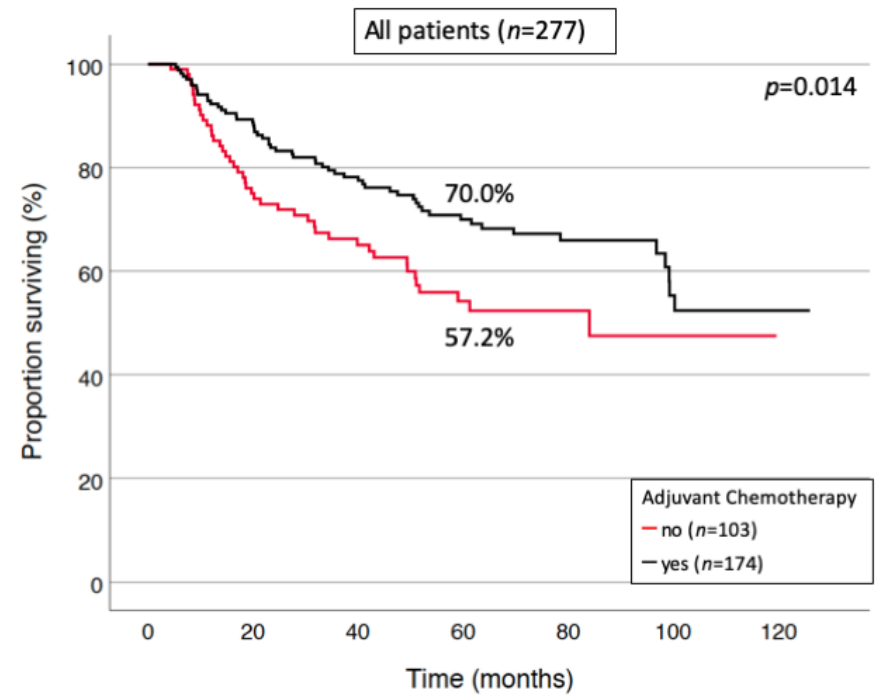

(a)

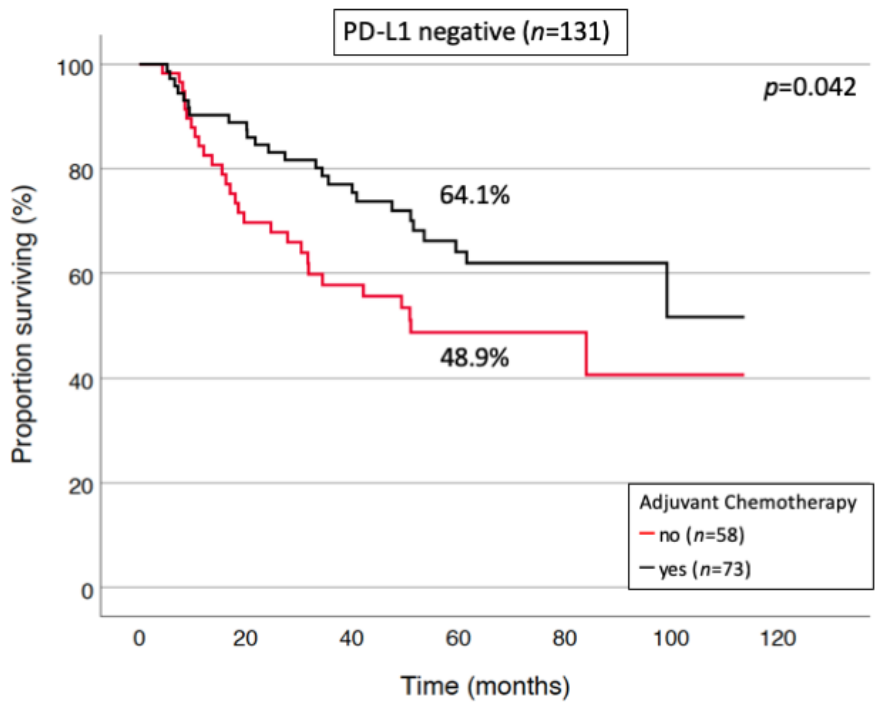

(b)

Figure 3. Cont. 


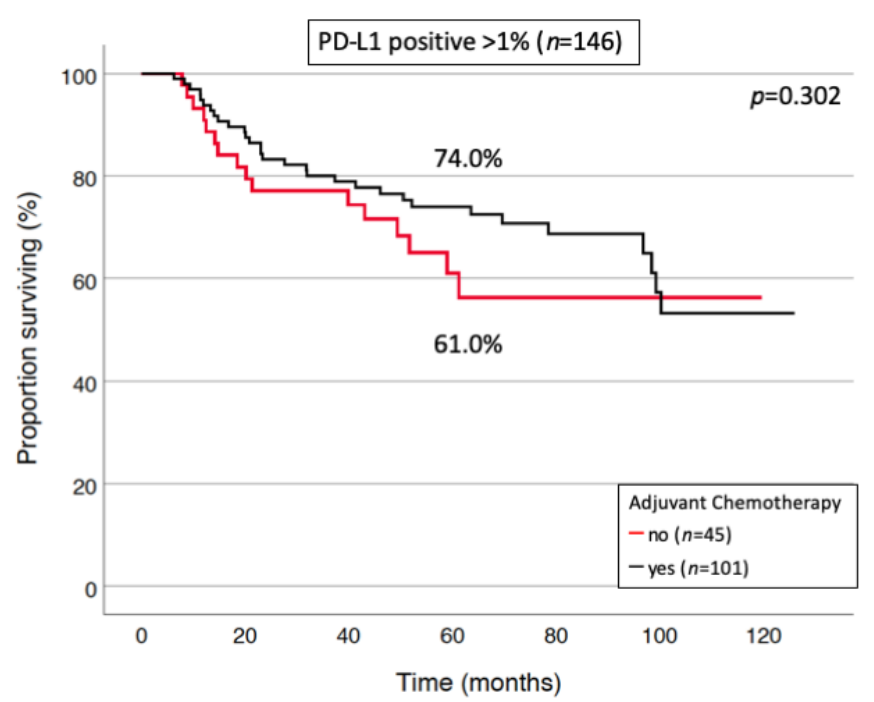

(c)

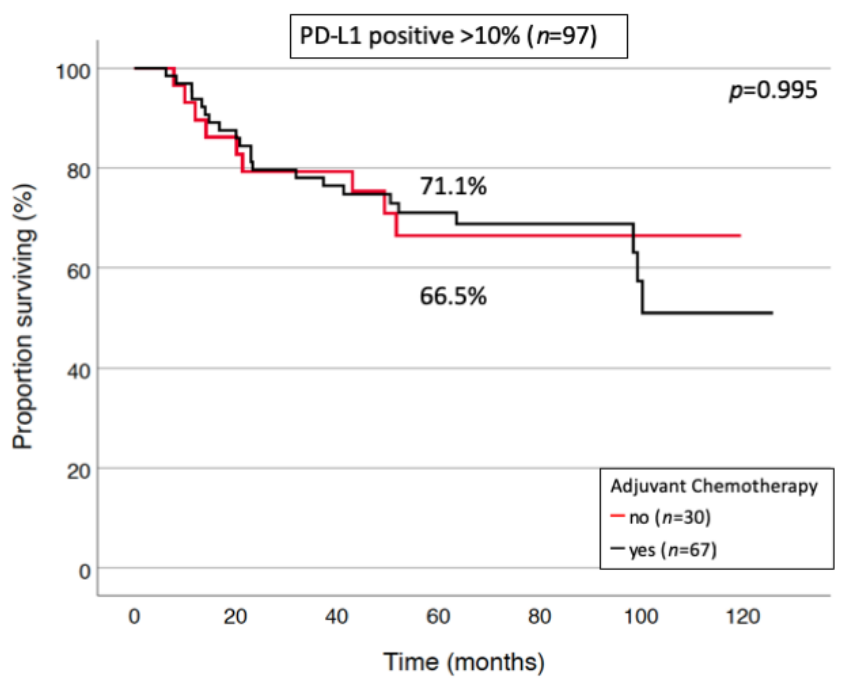

(d)

Figure 3. The effect of adjuvant chemotherapy in PD-L1 subgroups. Adjuvant chemotherapy improved survival in the entire study cohort (a) and in the PD-L1 negative subgroup (b). However, the beneficial effect of chemotherapy decreased in patients with PD-L1 expression $>1 \%$ (c) and $>10 \%$ (d).

However, different prognostic trends were observed among distinct histologic subtypes. PD-L1 was identified as a positive predictive factor for chemotherapy response in patients with adenocarcinoma histology $(p=0.019)$, but not squamous cell carcinoma $(p=0.155$, Figure $4 a, b)$. The latter small subgroup showed a trend towards inferior survival by adjuvant chemotherapy in patients with a PD-L1 expression of $>10 \%$.

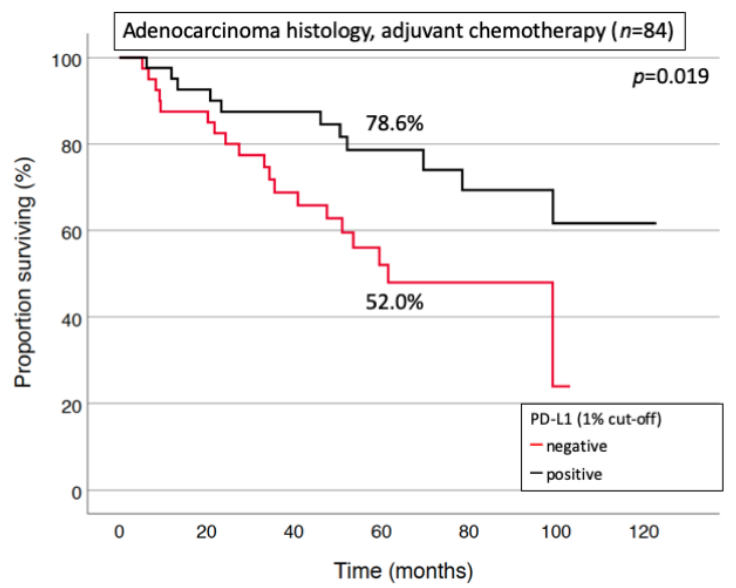

(a)

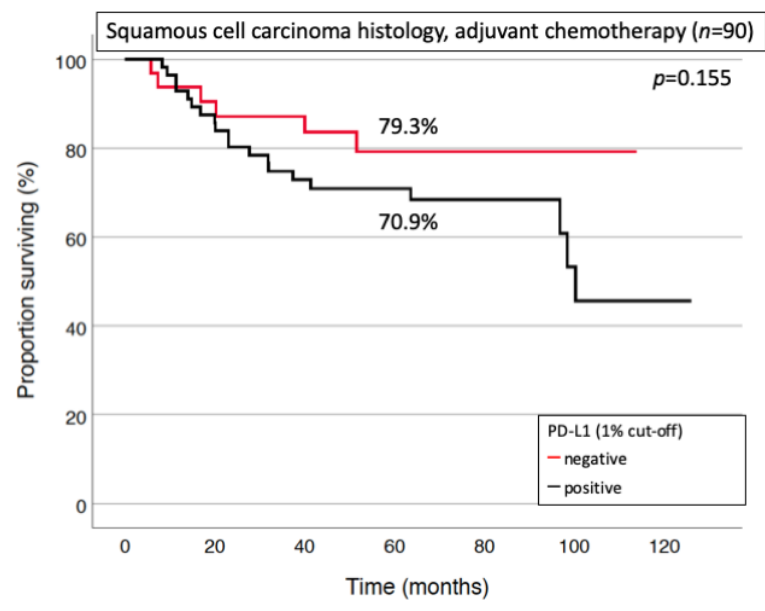

(b)

Figure 4. Positive PD-L1 status was associated with improved survival after chemotherapy in patients with adenocarcinoma (a), but not squamous cell carcinoma (b).

The multivariate analysis identified positive PD-L1 status $(p=0.007)$ and low tumor stage $(p=0.008)$ as independent prognostic factors for increased survival of patients with adenocarcinoma who received adjuvant chemotherapy (Table 3). Sex, younger age or better performance status were not associated with better survival in this subgroup. 
Table 3. Multivariate analysis of prognostic factors for TSS, subgroup adenocarcinoma and adjuvant chemotherapy.

\begin{tabular}{|c|c|c|c|}
\hline \multirow{2}{*}{ Variable } & \multicolumn{3}{|c|}{ Tumor-Specific Survival } \\
\hline & HR & $95 \% \mathrm{CI}$ & $p$-Value \\
\hline $\begin{array}{l}\text { Tumor Stage } \\
\text { IIA/IIB vs. IIIA }\end{array}$ & 0.36 & {$[0.17-0.77]$} & 0.008 \\
\hline $\begin{array}{l}\text { Sex } \\
\text { Male vs. female } \\
\text { PD-L1-status }\end{array}$ & 1.31 & {$[0.61-2.80]$} & 0.49 \\
\hline $\begin{array}{c}\text { Negative vs. positive } \\
\text { (at any cut-off) } \\
\text { Age }\end{array}$ & 2.92 & [1.33-6.39] & 0.007 \\
\hline $\begin{array}{c}>65 \text { years vs. }<65 \\
\text { years }\end{array}$ & 0.75 & {$[0.34-1.66]$} & 0.48 \\
\hline $\begin{array}{l}\text { Performance status } \\
\text { ECOG } 0 \text { vs. ECOG } 1\end{array}$ & 1.66 & {$[0.38-7.29]$} & 0.50 \\
\hline
\end{tabular}

Multivariate analysis in a subgroup of patients with adenocarcinoma histology and adjuvant treatment identified low tumor stage and positive PD-L1 expression as being independently associated with beneficial outcomes. CI, confidence interval. ECOG, Eastern Cooperative Oncology Group.

At the time of last analysis (January 2021), 140 patients (82.8\%) were free of tumor recurrence. 114 patients $(41.2 \%)$ of the entire cohort (277 patients) suffered from tumor relapse, and overall DFS was $57.7 \%$ at 5 years. Localized relapse was observed in 31 patients $(27.2 \%)$, distant isolated metastases in 61 patients $(53.5 \%)$ and multifocal or disseminated recurrence in 22 patients (19.3\%). Adjuvant chemotherapy treatment did not influence the risk of recurrence $(p=0.325)$. High tumor stage $(p<0.001)$ and adenocarcinoma histology $(p=0.007)$ were identified as independent negative factors predicting recurrence in multivariate analysis. Differences in sex, PD-L1 status and age were not identified as predictive for disease relapse. After chemotherapy, adenocarcinoma histology was associated with a higher risk of recurrence than squamous cell carcinoma $(p=0.042)$. Positive PD-L1 expression was deemed beneficial in this patient subgroup; however, it was not statistically significant $(p=0.081)$.

\section{Discussion}

The impact of PD-L1 expression on tumor tissue from a well-characterized clinical cohort of 277 patients with N1-NSCLC on survival was retrospectively analyzed.

Squamous cell histology, limited tumor stage and adjuvant chemotherapy were identified as positive predictive factors of survival for the entire cohort. However, subgroup analysis suggested a potential prognostic value of PD-L1 expression, specifically in patients with adenocarcinoma histology.

The extent of lymph node metastases strongly determines tumor staging and survival of lung cancer patients. In N1-NSCLC, primary surgery is the treatment of choice. However, indication for adjuvant standard chemotherapy insufficiently takes into consideration distinct prognostic subgroups that have been identified repetitively [3,21,22]. Different therapeutic options exist for the treatment of patients with metastasized NSCLC, depending on the histology and the biomarker-status. For instance, routine testing for PD-L1 is indispensable as checkpoint inhibitors have been approved for stage IV disease, either as mono- or combination first-line therapy $[23,24]$. A paradigm shift in early lung cancer treatment is of current interest, as the first promising results on adjuvant anti-PD1/-PDL1 therapy upfront surgery have been reported $[12,13]$. However, the role of adjuvant anti-PD1 immunotherapy has yet not been adequately addressed, and few phase III trials have been registered so far, but final analyses are pending (NCT02504372, NCT02273375, NCT02595944, NCT02486718, clinicaltrials.gov, accessed on 13 March 2021). 
How far PD-L1 qualifies as a prognostic biomarker is of great interest in the literature, and both positive [25-28] and negative associations [29-31] with survival have been reported. A recently published meta-analysis by Tuminello et al. included more than 10,000 surgical patients (stages I-III NSCLC), and high PD-L1 expression was associated with poor survival, statistically significant in adenocarcinoma, but not in squamous cell carcinoma [32]. The authors discuss a potential bias by lacking information on concurrent systemic therapies (adjuvant and neoadjuvant). Second, data on specific inclusion and exclusion criteria of the selected studies was missing in $50 \%$ of the patients.

Positive PD-L1-status showed a trend towards better outcomes in univariate analysis of our entire patient cohort. The proportion of positive PD-L1 patients was significantly higher in patients that were treated with adjuvant chemotherapy. Notably, adjuvant chemotherapy and low tumor stage were identified as significant beneficial factors in multivariate testing of all patients. However, positive PD-L1 was predictive for improved survival after chemotherapy in multivariate analysis of patients with adenocarcinoma histology, but not squamous cell carcinoma. A prognostic impact of PD-L1 in specific subgroups of surgical NSCLC has been also reported for patients with high marker expression $(>50 \%$ ) [26] or with N2-lmyph node metastases [28]. Schmidt et al. reported on improved overall survival in a subgroup with squamous cell carcinoma histology, lymph node metastases and adjuvant therapy [27]. Yang et al. analyzed 163 patients following resection of stage I adenocarcinoma and found a correlation between PD-L1 expression and prolonged relapse-free survival, but not overall survival [33].

The variety of results and different prognostic impact of PD-L1 in specific subgroups warrant a controversial discussion on PD-L1 as a predictive marker. It is important to realize that different anti-PD-L1 capture antibodies, different thresholds to determine PD-L1 positivity and individual characteristics, such as ethnicity or tumor histology, may affect prognostic estimations. For instance, different proportions of PD-L1-positive tumors for distinct histological NSCLC subtypes have been reported. A higher rate of PD-L1 positive cells in resected tumors with adenocarcinoma histology than squamous cell carcinoma was found by Mu et al. ( $65 \%$ vs. $44 \%, p=0.032$ ) [34]. However, others observed a higher proportion of PD-L1 positive tumors in surgical cohorts with squamous cell histology [27,29,35]. These results were in accordance with our series that identified a predominance of PD-L1 expression in squamous cell carcinomas. In this specific smoking-associated entity, the potential that accompanied smoking induced acquired somatic mutations along with oxidative stress that may result in the observed elevated expression of PD-L1 protein [36], thus leading to durable PD-1 antibody response in clinical studies [37-39].

The benefit of adjuvant chemotherapy in the entire N1 cohort diminished with increasing PD-L1 expression levels. Moreover, a trend towards inferior outcomes has been observed for patients with squamous cell carcinoma histology and elevated PD-L1. How far adjuvant immunotherapy can be alternatively administered has to be addressed in the future. However, the benefit of checkpoint-inhibitory therapy in PD-L1 positive (at any threshold) advanced and metastatic NSCLC is undisputed [24]. Our analysis identified elevated PD-L1 as a positive prognostic predictor in adenocarcinomas treated with adjuvant chemotherapy. In a neoadjuvant setting, chemotherapy has been found to induce changes in the immune microenvironment promoting antitumor immunity [40]. Consequently, further research is warranted to evolve potential synergistic effects of combination chemo-/immunotherapy and to identify subgroups susceptible for responses in multimodal treatment concepts with curative intent.

Differences in survival depending on patients' ethnicity and race have been repetitively reported among various malignancies, including lung cancer [41]. For instance, the influence of heterogeneous prognostic characteristics, such as smoking status, prevalence of genomic alterations, and response to chemotherapy, were discussed on the course of the disease in a comparative study of Asian and non-Asian individuals [42,43]. Ethnic disparities were also apparent in two meta-analyses on the predictive role of PD-L1. Among these, PD-L1 expression was associated with poor survival. Of note, the majority of source 
data were from Asian patients [32,44]. Only a few series with Caucasian patients were included within adversely identifying PD-L1-expression as a favorable predictor [26,27,45]. The results of our series assimilate the existing European results; however, the complex pathomechanisms accountable for the observed ethnic disparities are under current investigation. Conclusively, a number of covariates, such as heterogeneity in the molecular landscape, must be deemed responsible for the observed differences [46,47].

The indication for immune checkpoint inhibitor-therapy in lung cancer is strongly linked with PD-L1 assessment. National and international definitions of PD-L1 testing in terms of used staining antibodies and thresholds for positivity quantitative analyses have been addressed and defined recently [20,48,49]. However, clinically approved positive cutoffs range from 1 to $50 \%$ and were inconsistently used in retrospective studies. The difficulty in determining a clinically appropriate threshold to define a positive, predictive test was discussed by Kerr et al. The authors propose avoiding very low staining thresholds $(1-5 \%)$, as these would more likely inaccurately reflect the patient's overall tumor burden because of intra-tumoral heterogeneity and a higher risk of inconsistencies in scoring [50]. These suggestions are supported by a series from Illie et al. which revealed major discordances between diagnostic biopsies and surgical specimens in $48 \%$ of cases. In all cases, the biopsy specimens underestimated the PD-L1 status observed on the whole tissue sample [51]. Heterogeneous PD-L1 expression was also found in our series, as positive staining was restricted to either the tumor core or the invasive margin in $18 \%$ of patients. Second, a deviation of $10 \%$ or more in staining extent was found in $44.5 \%$ of PD-L1 positive patients, depending on the analyzed region (tumor core or invasive margin). In a clinical scenario, diagnostic procedures (e.g., transbronchial biopsy, needle-core biopsy) should consider these findings and counter intra-tumoral heterogeneity by sequential biopsies from different tumor regions.

Standard adjuvant treatment for nodal positive patients comprises platinum-based combination chemotherapy irrespective of histological subtype or distinct predictive biomarkers. Chemotherapy failed to improve survival in our series in patients with a PD-L1 expression of $10 \%$ or more. However, this observation could be explained by opposed survival impact after stratification towards histological subtypes, with significant superior results in the adenocarcinoma subgroup.

The study has limitations: due to its retrospective design and the selected patient cohort, the results of PD-L1 analysis were not available at the timepoint of interdisciplinary decision towards adjuvant treatment. The observed trend towards better survival of PD-L1 positive patients in the entire cohort is assumed to be biased by the higher proportion of PD-L1 positive tumors in patients receiving chemotherapy, which was identified as a strong positive prognostic factor. However, analysis of all patients receiving standard adjuvant systemic treatment revealed PD-L1 protein analysis as potentially predictive for relevant subgroups of limited stage NSCLC.

\section{Conclusions}

PD-L1 expression was identified as a positive predictor for survival in patients with an adenocarcinoma histology receiving adjuvant chemotherapy. Moreover, a trend towards negative impact on survival was observed in PD-L1 positive patients with squamous cell histology. A prognostic relevance of PD-L1 expression in the adjuvant treatment course can be hypothesized. However, the sample size of our cohort was small and the clinical impact of our findings has to be further elucidated. Compared to the metastatic stage, systemic treatment following curative intent surgery should consider histology and PD-L1 expression status as potential prognostic factors towards individualized adjuvant therapy. Ongoing research in this context is urgently needed to address the utility of PD-L1 and other potential predictive factors in the postoperative setting.

Author Contributions: Conceptualization, F.E., M.K. and M.E.E.; methodology, F.E., L.V.K. and P.C.; software, F.E., M.K., K.K. and T.M.; validation, F.E., M.K. and K.K.; resources, T.M., M.K. and C.Z.; writing—original draft preparation, F.E.; writing—review \& editing, M.K., L.V.K., K.K., P.C., H.W. 
and M.E.E.; visualization, F.E. and M.K.; supervision, M.E.E. and H.W. All authors have read and agreed to the published version of the manuscript.

Funding: This research received no external funding.

Institutional Review Board Statement: The study was conducted according to the guidelines of the Declaration of Helsinki and approved by the Institutional Review Board of the University of Heidelberg (S-174/2019).

Informed Consent Statement: Not applicable.

Data Availability Statement: Data are available on request due to privacy and ethical restrictions.

Acknowledgments: We thank S. Kobinger (Heidelberg) for the kind help with data acquisition and database management.

Conflicts of Interest: The authors declare no conflict of interest.

\section{References}

1. Bray, F.; Ferlay, J.; Soerjomataram, I.; Siegel, R.L.; Torre, L.A.; Jemal, A. Global cancer statistics 2018: GLOBOCAN estimates of incidence and mortality worldwide for 36 cancers in 185 countries. CA Cancer J. Clin. 2018, 68, 394-424. [CrossRef]

2. Cruz, C.; Afonso, M.; Oliveiros, B.; Pego, A. Recurrence and Risk Factors for Relapse in Patients with Non-Small Cell Lung Cancer Treated by Surgery with Curative Intent. Oncology 2017, 92, 347-352. [CrossRef] [PubMed]

3. Asamura, H.; Chansky, K.; Crowley, J.; Goldstraw, P.; Rusch, V.W.; Vansteenkiste, J.F.; Watanabe, H.; Wu, Y.L.; Zielinski, M.; Ball, D.; et al. The International Association for the Study of Lung Cancer Lung Cancer Staging Project: Proposals for the Revision of the N Descriptors in the Forthcoming 8th Edition of the TNM Classification for Lung Cancer. J. Thorac. Oncol. 2015, 10, 1675-1684. [CrossRef]

4. Rusch, V.W.; Asamura, H.; Watanabe, H.; Giroux, D.J.; Rami-Porta, R.; Goldstraw, P. The IASLC lung cancer staging project: A proposal for a new international lymph node map in the forthcoming seventh edition of the TNM classification for lung cancer. $J$. Thorac. Oncol. 2009, 4, 568-577. [CrossRef] [PubMed]

5. Arriagada, R.; Bergman, B.; Dunant, A.; Le Chevalier, T.; Pignon, J.P.; Vansteenkiste, J.; International Adjuvant Lung Cancer Trial Collaborative Group. Cisplatin-based adjuvant chemotherapy in patients with completely resected non-small-cell lung cancer. $N$. Engl. J. Med. 2004, 350, 351-360. [CrossRef] [PubMed]

6. Arriagada, R.; Dunant, A.; Pignon, J.P.; Bergman, B.; Chabowski, M.; Grunenwald, D.; Kozlowski, M.; Le Pechoux, C.; Pirker, R.; Pinel, M.I.; et al. Long-term results of the international adjuvant lung cancer trial evaluating adjuvant Cisplatin-based chemotherapy in resected lung cancer. J. Clin. Oncol. 2010, 28, 35-42. [CrossRef]

7. Herbst, R.S.; Baas, P.; Kim, D.W.; Felip, E.; Perez-Gracia, J.L.; Han, J.Y.; Molina, J.; Kim, J.H.; Arvis, C.D.; Ahn, M.J.; et al. Pembrolizumab versus docetaxel for previously treated, PD-L1-positive, advanced non-small-cell lung cancer (KEYNOTE-010): A randomised controlled trial. Lancet 2016, 387, 1540-1550. [CrossRef]

8. Reck, M.; Rodriguez-Abreu, D.; Robinson, A.G.; Hui, R.; Csoszi, T.; Fulop, A.; Gottfried, M.; Peled, N.; Tafreshi, A.; Cuffe, S.; et al. Pembrolizumab versus Chemotherapy for PD-L1-Positive Non-Small-Cell Lung Cancer. N. Engl. J. Med. 2016, 375, 1823-1833. [CrossRef] [PubMed]

9. Antonia, S.J.; Villegas, A.; Daniel, D.; Vicente, D.; Murakami, S.; Hui, R.; Yokoi, T.; Chiappori, A.; Lee, K.H.; de Wit, M.; et al. Durvalumab after Chemoradiotherapy in Stage III Non-Small-Cell Lung Cancer. N. Engl. J. Med. 2017, 377, 1919-1929. [CrossRef]

10. Deslypere, G.; Gullentops, D.; Wauters, E.; Vansteenkiste, J. Immunotherapy in non-metastatic non-small cell lung cancer: Can the benefits of stage IV therapy be translated into earlier stages? Ther. Adv. Med. Oncol. 2018, 10, 1758835918772810. [CrossRef]

11. Postmus, P.E.; Kerr, K.M.; Oudkerk, M.; Senan, S.; Waller, D.A.; Vansteenkiste, J.; Escriu, C.; Peters, S. Early and locally advanced non-small-cell lung cancer (NSCLC): ESMO Clinical Practice Guidelines for diagnosis, treatment and follow-up. Ann. Oncol. 2017, 28, iv1-iv21. [CrossRef]

12. Forde, P.M.; Chaft, J.E.; Smith, K.N.; Anagnostou, V.; Cottrell, T.R.; Hellmann, M.D.; Zahurak, M.; Yang, S.C.; Jones, D.R.; Broderick, S.; et al. Neoadjuvant PD-1 Blockade in Resectable Lung Cancer. N. Engl. J. Med. 2018, 378, 1976-1986. [CrossRef] [PubMed]

13. Provencio, M.; Nadal, E.; Insa, A.; Garcia-Campelo, M.R.; Casal-Rubio, J.; Domine, M.; Majem, M.; Rodriguez-Abreu, D.; Martinez-Marti, A.; De Castro Carpeno, J.; et al. Neoadjuvant chemotherapy and nivolumab in resectable non-small-cell lung cancer (NADIM): An open-label, multicentre, single-arm, phase 2 trial. Lancet Oncol. 2020, 21, 1413-1422. [CrossRef]

14. Pirker, R.; Filipits, M. Adjuvant Therapy in Patients With Completely Resected Non-small-cell Lung Cancer: Current Status and Perspectives. Clin. Lung Cancer 2019, 20,1-6. [CrossRef]

15. Bai, R.; Li, L.; Chen, X.; Chen, N.; Song, W.; Cui, J. Neoadjuvant and Adjuvant Immunotherapy: Opening New Horizons for Patients With Early-Stage Non-small Cell Lung Cancer. Front. Oncol. 2020, 10, 575472. [CrossRef] [PubMed]

16. Bodor, J.N.; Boumber, Y.; Borghaei, H. Biomarkers for immune checkpoint inhibition in non-small cell lung cancer (NSCLC). Cancer 2020, 126, 260-270. [CrossRef] [PubMed] 
17. Travis, W.D.; Brambilla, E.; Nicholson, A.G.; Yatabe, Y.; Austin, J.H.; Beasley, M.B.; Chirieac, L.R.; Dacic, S.; Duhig, E.; Flieder, D.B.; et al. The 2015 World Health Organization Classification of Lung Tumors: Impact of Genetic, Clinical and Radiologic Advances Since the 2004 Classification. J. Thorac. Oncol. 2015, 10, 1243-1260. [CrossRef] [PubMed]

18. Lisenko, K.; Leichsenring, J.; Zgorzelski, C.; Longuespee, R.; Casadonte, R.; Harms, A.; Kazdal, D.; Stenzinger, A.; Warth, A.; Kriegsmann, M. Qualitative Comparison Between Carrier-based and Classical Tissue Microarrays. Appl. Immunohistochem. Mol. Morphol. 2017, 25, e74-e79. [CrossRef] [PubMed]

19. Casadonte, R.; Longuespee, R.; Kriegsmann, J.; Kriegsmann, M. MALDI IMS and Cancer Tissue Microarrays. Adv. Cancer Res. 2017, 134, 173-200. [CrossRef]

20. Lantuejoul, S.; Sound-Tsao, M.; Cooper, W.A.; Girard, N.; Hirsch, F.R.; Roden, A.C.; Lopez-Rios, F.; Jain, D.; Chou, T.Y.; Motoi, N.; et al. PD-L1 Testing for Lung Cancer in 2019: Perspective From the IASLC Pathology Committee. J. Thorac. Oncol. 2020, 15, 499-519. [CrossRef]

21. Wei, S.; Asamura, H.; Kawachi, R.; Sakurai, H.; Watanabe, S. Which is the better prognostic factor for resected non-small cell lung cancer: The number of metastatic lymph nodes or the currently used nodal stage classification? J. Thorac. Oncol. 2011, 6, 310-318. [CrossRef] [PubMed]

22. Eichhorn, F.; Klotz, L.V.; Muley, T.; Kobinger, S.; Winter, H.; Eichhorn, M.E. Prognostic relevance of regional lymph-node distribution in patients with N1-positive non-small cell lung cancer: A retrospective single-center analysis. Lung Cancer 2019, 138, 95-101. [CrossRef] [PubMed]

23. Gandhi, L.; Rodriguez-Abreu, D.; Gadgeel, S.; Esteban, E.; Felip, E.; De Angelis, F.; Domine, M.; Clingan, P.; Hochmair, M.J.; Powell, S.F.; et al. Pembrolizumab plus Chemotherapy in Metastatic Non-Small-Cell Lung Cancer. N. Engl. J. Med. 2018, 378, 2078-2092. [CrossRef] [PubMed]

24. Mok, T.S.K.; Wu, Y.L.; Kudaba, I.; Kowalski, D.M.; Cho, B.C.; Turna, H.Z.; Castro, G., Jr.; Srimuninnimit, V.; Laktionov, K.K.; Bondarenko, I.; et al. Pembrolizumab versus chemotherapy for previously untreated, PD-L1-expressing, locally advanced or metastatic non-small-cell lung cancer (KEYNOTE-042): A randomised, open-label, controlled, phase 3 trial. Lancet 2019, 393, 1819-1830. [CrossRef]

25. Velcheti, V.; Schalper, K.A.; Carvajal, D.E.; Anagnostou, V.K.; Syrigos, K.N.; Sznol, M.; Herbst, R.S.; Gettinger, S.N.; Chen, L.; Rimm, D.L. Programmed death ligand-1 expression in non-small cell lung cancer. Lab. Investig. 2014, 94, 107-116. [CrossRef]

26. Cooper, W.A.; Tran, T.; Vilain, R.E.; Madore, J.; Selinger, C.I.; Kohonen-Corish, M.; Yip, P.; Yu, B.; O’Toole, S.A.; McCaughan, B.C.; et al. PD-L1 expression is a favorable prognostic factor in early stage non-small cell carcinoma. Lung Cancer 2015, 89, 181-188. [CrossRef]

27. Schmidt, L.H.; Kummel, A.; Gorlich, D.; Mohr, M.; Brockling, S.; Mikesch, J.H.; Grunewald, I.; Marra, A.; Schultheis, A.M.; Wardelmann, E.; et al. PD-1 and PD-L1 Expression in NSCLC Indicate a Favorable Prognosis in Defined Subgroups. PLoS ONE 2015, 10, e0136023. [CrossRef]

28. Ameratunga, M.; Asadi, K.; Lin, X.; Walkiewicz, M.; Murone, C.; Knight, S.; Mitchell, P.; Boutros, P.; John, T. PD-L1 and Tumor Infiltrating Lymphocytes as Prognostic Markers in Resected NSCLC. PLoS ONE 2016, 11, e0153954. [CrossRef] [PubMed]

29. Takada, K.; Okamoto, T.; Toyokawa, G.; Kozuma, Y.; Matsubara, T.; Haratake, N.; Akamine, T.; Takamori, S.; Katsura, M.; Shoji, F.; et al. The expression of PD-L1 protein as a prognostic factor in lung squamous cell carcinoma. Lung Cancer 2017, 104, 7-15. [CrossRef]

30. Takada, K.; Okamoto, T.; Shoji, F.; Shimokawa, M.; Akamine, T.; Takamori, S.; Katsura, M.; Suzuki, Y.; Fujishita, T.; Toyokawa, G.; et al. Clinical Significance of PD-L1 Protein Expression in Surgically Resected Primary Lung Adenocarcinoma. J. Thorac. Oncol. 2016, 11, 1879-1890. [CrossRef] [PubMed]

31. Cha, Y.J.; Kim, H.R.; Lee, C.Y.; Cho, B.C.; Shim, H.S. Clinicopathological and prognostic significance of programmed cell death ligand-1 expression in lung adenocarcinoma and its relationship with p53 status. Lung Cancer 2016, 97, 73-80. [CrossRef]

32. Tuminello, S.; Sikavi, D.; Veluswamy, R.; Gamarra, C.; Lieberman-Cribbin, W.; Flores, R.; Taioli, E. PD-L1 as a prognostic biomarker in surgically resectable non-small cell lung cancer: A meta-analysis. Transl. Lung Cancer Res. 2020, 9, $1343-1360$. [CrossRef]

33. Yang, C.Y.; Lin, M.W.; Chang, Y.L.; Wu, C.T.; Yang, P.C. Programmed cell death-ligand 1 expression in surgically resected stage I pulmonary adenocarcinoma and its correlation with driver mutations and clinical outcomes. Eur. J. Cancer 2014, 50, 1361-1369. [CrossRef]

34. Mu, C.Y.; Huang, J.A.; Chen, Y.; Chen, C.; Zhang, X.G. High expression of PD-L1 in lung cancer may contribute to poor prognosis and tumor cells immune escape through suppressing tumor infiltrating dendritic cells maturation. Med. Oncol. 2011, 28, 682-688. [CrossRef]

35. Lin, G.; Fan, X.; Zhu, W.; Huang, C.; Zhuang, W.; Xu, H.; Lin, X.; Hu, D.; Huang, Y.; Jiang, K.; et al. Prognostic significance of PD-L1 expression and tumor infiltrating lymphocyte in surgically resectable non-small cell lung cancer. Oncotarget 2017, 8 , 83986-83994. [CrossRef] [PubMed]

36. Calles, A.; Liao, X.; Sholl, L.M.; Rodig, S.J.; Freeman, G.J.; Butaney, M.; Lydon, C.; Dahlberg, S.E.; Hodi, F.S.; Oxnard, G.R.; et al. Expression of PD-1 and Its Ligands, PD-L1 and PD-L2, in Smokers and Never Smokers with KRAS-Mutant Lung Cancer. J. Thorac. Oncol. 2015, 10, 1726-1735. [CrossRef] [PubMed] 
37. Kim, M.Y.; Koh, J.; Kim, S.; Go, H.; Jeon, Y.K.; Chung, D.H. Clinicopathological analysis of PD-L1 and PD-L2 expression in pulmonary squamous cell carcinoma: Comparison with tumor-infiltrating T cells and the status of oncogenic drivers. Lung Cancer 2015, 88, 24-33. [CrossRef]

38. Rizvi, N.A.; Hellmann, M.D.; Snyder, A.; Kvistborg, P.; Makarov, V.; Havel, J.J.; Lee, W.; Yuan, J.; Wong, P.; Ho, T.S.; et al. Cancer immunology. Mutational landscape determines sensitivity to PD-1 blockade in non-small cell lung cancer. Science 2015, 348, 124-128. [CrossRef] [PubMed]

39. Brahmer, J.; Reckamp, K.L.; Baas, P.; Crino, L.; Eberhardt, W.E.; Poddubskaya, E.; Antonia, S.; Pluzanski, A.; Vokes, E.E.; Holgado, E.; et al. Nivolumab versus Docetaxel in Advanced Squamous-Cell Non-Small-Cell Lung Cancer. N. Engl. J. Med. 2015, 373, 123-135. [CrossRef]

40. Alexander, A.C.; Ali, J.; McDevitt-Murphy, M.E.; Forde, D.R.; Stockton, M.; Read, M.; Ward, K.D. Racial Differences in Posttraumatic Stress Disorder Vulnerability Following Hurricane Katrina Among a Sample of Adult Cigarette Smokers from New Orleans. J. Racial Ethn. Health Disparities 2017, 4, 94-103. [CrossRef] [PubMed]

41. Zhang, C.; Zhang, C.; Wang, Q.; Li, Z.; Lin, J.; Wang, H. Differences in Stage of Cancer at Diagnosis, Treatment, and Survival by Race and Ethnicity Among Leading Cancer Types. JAMA Netw. Open 2020, 3, e202950. [CrossRef] [PubMed]

42. Yatabe, Y.; Kerr, K.M.; Utomo, A.; Rajadurai, P.; Tran, V.K.; Du, X.; Chou, T.Y.; Enriquez, M.L.; Lee, G.K.; Iqbal, J.; et al. EGFR mutation testing practices within the Asia Pacific region: Results of a multicenter diagnostic survey. J. Thorac. Oncol. 2015, 10, 438-445. [CrossRef] [PubMed]

43. Pao, W.; Miller, V.A. Epidermal growth factor receptor mutations, small-molecule kinase inhibitors, and non-small-cell lung cancer: Current knowledge and future directions. J. Clin. Oncol. 2005, 23, 2556-2568. [CrossRef]

44. Pan, Z.K.; Ye, F.; Wu, X.; An, H.X.; Wu, J.X. Clinicopathological and prognostic significance of programmed cell death ligand1 (PD-L1) expression in patients with non-small cell lung cancer: A meta-analysis. J. Thorac. Dis. 2015, 7, 462-470. [CrossRef]

45. Zaric, B.; Brcic, L.; Buder, A.; Brandstetter, A.; Buresch, J.O.; Traint, S.; Kovacevic, T.; Stojsic, V.; Perin, B.; Pirker, R.; et al. PD-1 and PD-L1 Protein Expression Predict Survival in Completely Resected Lung Adenocarcinoma. Clin. Lung Cancer 2018, 19, e957-e963. [CrossRef]

46. Heath, E.I.; Lynce, F.; Xiu, J.; Ellerbrock, A.; Reddy, S.K.; Obeid, E.; Liu, S.V.; Bollig-Fischer, A.; Separovic, D.; Vanderwalde, A. Racial Disparities in the Molecular Landscape of Cancer. Anticancer Res. 2018, 38, 2235-2240. [CrossRef] [PubMed]

47. McIntyre, A.; Ganti, A.K. Lung cancer-A global perspective. J. Surg. Oncol. 2017, 115, 550-554. [CrossRef]

48. Scheel, A.H.; Baenfer, G.; Baretton, G.; Dietel, M.; Diezko, R.; Henkel, T.; Heukamp, L.C.; Jasani, B.; Johrens, K.; Kirchner, T.; et al. Interlaboratory concordance of PD-L1 immunohistochemistry for non-small-cell lung cancer. Histopathology 2018, 72, 449-459. [CrossRef]

49. Williams, G.H.; Nicholson, A.G.; Snead, D.R.J.; Thunnissen, E.; Lantuejoul, S.; Cane, P.; Kerr, K.M.; Loddo, M.; Scott, M.L.J.; Scorer, P.W.; et al. Interobserver Reliability of Programmed Cell Death Ligand-1 Scoring Using the VENTANA PD-L1 (SP263) Assay in NSCLC. J. Thorac. Oncol. 2020, 15, 550-555. [CrossRef]

50. Kerr, K.M.; Tsao, M.S.; Nicholson, A.G.; Yatabe, Y.; Wistuba, I.I.; Hirsch, F.R. Programmed Death-Ligand 1 Immunohistochemistry in Lung Cancer: In what state is this art? J. Thorac. Oncol. 2015, 10, 985-989. [CrossRef]

51. Ilie, M.; Long-Mira, E.; Bence, C.; Butori, C.; Lassalle, S.; Bouhlel, L.; Fazzalari, L.; Zahaf, K.; Lalvee, S.; Washetine, K.; et al. Comparative study of the PD-L1 status between surgically resected specimens and matched biopsies of NSCLC patients reveal major discordances: A potential issue for anti-PD-L1 therapeutic strategies. Ann. Oncol. 2016, 27, 147-153. [CrossRef] [PubMed] 